\title{
Precision medicine, imprecision medicine- two ends of a biological telescope?
} Health Design

\section{EDITORIAL}

\section{Christopher McGrath}

1. University of Otago, Dunedin, Otago, New Zealand

To Cite: McGrath MC. Precision medicine, imprecision medicine-two ends of a biological telescope? JHD. 2017;2(1):5-8. https://doi.org/10.21853/JHD.2017.15

\section{Corresponding Author:}

M. Christopher McGrath

Country Practice Ltd.

East Taieri, Mosgiel 9024, NZ

countrypracticeltd@gmail.com

\section{Copyright:}

(c) 2017 The Authors. Published by Archetype Health Pty Ltd.. This is an open access article under the CC BY-NC-ND 4.0 license.

\section{SUMMARY}

Epidemiology may be used to project information derived from select populations into both "evidence-based" individual care and patient-centred health policy. An institutionalised perception appears to exist that regardless of the degree of individual and public "buy-in", it is simply never enough. On the other hand, a natural ceiling in personal and public "buy-in" may exist because the daily expression of living embodies a continuous personal stream of habituating threat and risk. Now, for the first time in human history a personalised genetic profile may provide a truly precise and patient-centric approach to health care that leads to individually specific awareness of prevention and personal risk mitigation. In the fullness of time, it may further the development of an intellectually honest and potentially more effective address of the individual health-span gamble that many seem instinctively willing to play from a population based, "one-shoe-fits-all" approach.

\section{Key Words}

Precision medicine; epidemiology; risk; genomic; personalised; individual; public health; environmental; patient-centred; patient centric

\section{INTRODUCTION}

The innovation of precision medicine holds the potential promise of a scientific, personalised, patient-centred and patient-centric, holistic approach that, for the first time in human history, may provide an individual with the detailed view of their genetic markers and predispositions in the context of their environment and actions. That it may individually lead to a more precise and individual focus for prevention appears to be without doubt. This evolving opportunity enabled by knowledge and technology may see precise personal information and its consequent specific motivation replace a more usual patient-centred diet of information predicated on a cohort risk analysis and spur of threat-borne fear.

Whether or not one has used a telescope, an instinctive understanding of its purpose exists through a common understanding of its design. By viewing a scene through the eyepiece, an image at once appears closer and detail hitherto unseen now appears visible. If the scene is instead viewed through the objective lens of the instrument, an impractically small image is seen in which detail is absent. Indeed, this idea is so familiar that it has become a figure of speech. Perceiving a problem through the wrong end of the telescope is a well-understood metaphor.

With the advent and growth of precision medicine ${ }^{1}$ described as "an emerging approach for disease treatment and prevention, which takes into account individual variability in environment, lifestyle and genes for each person", 2 we witness the installation of greater scientific meaning to the hackneyed phrases "holistic" and "patient-centred". The National Institutes of Health Precision Medicine Initiative (NIH PMI) "All of Us" has been funded with USD \$215 million and a stated aim of capturing the data from one million participants. ${ }^{3}$ The PMI Cohort Program will be

... a participant-engaged, data-driven enterprise supporting research at the intersection of human biology, behavior, genetics, environment, data science and computation, and much more to produce new knowledge with the goal of developing more effective ways to prolong health and treat disease. ${ }^{3}$

In contradistinction, present day health care is said to epitomise "imprecision medicine" ${ }^{4}$ where, in a sense, the 
biological telescope is inverted in epidemiological analysis. The results are not so impressive:

Current estimates show that only $20 \%$ of patients benefit from the 20 most prescribed drugs, and 12 million serious diagnostic errors occur each year. Even basic screening modalities such as mammography and prostate-specific antigen tests yield a high rate of false positives. $^{4}$

Individual biology is predicated upon the statistical risk derived from a cohort and its associations, something that patients often intuitively appreciate and health professionals know well.

To an individual patient or in public health, evidencebased "risk-mongering" may form the basis of today's professional advice and health policy, but have you noticed that it is inevitably accompanied by researchers, health professionals, public health advisers, and politicians bemoaning the guaranteed failure to achieve a preconceived target of individual or public adherence? The circularity of this observation is as worrying as it is obvious-"Evidence-based policy cannot be separated from policy-based evidence" ${ }^{5}$ lending itself readily to the development of the distorted societal state of "hypocognition". ${ }^{5}$ Moreover, a fundamental disconnect appears between the tellers and the told, with the latter recognising that a statement of calculated statistical risk is not an absolute truth capable of reflecting an accurate personal description of an individual's biology or context. I believe that both patients and the wider public intuitively recognise this, instinctively weighing perceived risk against the stated calculated risk when undertaking health decision.

Human beings execute an unending stream of personal decisions predicated on an instinctive or sometimes more formal evaluation of the risk-benefit ratio. In this personal process, absolute risk as opposed to relative risk appears to be the currency of choice, though the latter inevitably remains the omnipresent marketing megaphone and chief currency of "risk-mongering". The two currencies do not have equivalence. While absolute risk is founded on an informational gold standard, relative risk is in comparison a kind of fiat currency, that is, an intrinsically worthless currency founded upon a perceived marketing value rather than one based on any intrinsic or representative absolute value. Take, for example, the recent changes in public policy around fat and sugar. Butter once demonized is now not so bad in moderation. Sugar is now the new butter.

In the statistical analysis around risk, have we forgotten that patients are human beings cortically hardwired to accept a multitude of risk that permeates every single aspect of their lives and their behaviour on a daily basis? Telling a lie and weighing the odds on being found out, or gambling upon not arriving late, are just trivial examples of a constant living stream of risk-benefit analysis that we all instinctively and routinely undertake. The constellation of well-publicised risks potentially acting on an individual's health $\operatorname{span}^{6}$ may inform an individual's existence, but it joins a very long queue of risk. After all, human existence is finite and imbued from birth with an absolute risk of 100 per cent in the certainty of mortality. While personal tolerance may vary when an individual weighs a threat to their health-span, human behaviour exemplifies risk and more, it appears extremely well adapted to it. On the other hand, contemporaneous societal mores that appear inclined toward a social construct that is more notably risk averse. ${ }^{?}$

Tomasetti and Vogelstein disturbed the guardians of public health with the publication of their illuminating research in Science in January 2015, which quantified the genetic and environmental contribution to a range of common cancers displayed in a telling graphic image of stochastic (replicative) factors versus environmental and inherited factors. ${ }^{8}$ Their abstract states:

These results suggest that only a third of the variation in cancer risk among tissues is attributable to environmental factors or inherited predispositions. The majority is due to 'bad luck', that is, random mutations arising during DNA replication in normal, noncancerous stem cells. This is important not only for understanding the disease but also for designing strategies to limit the mortality it causes. ${ }^{8}$

They further explained:

1. All cancers are caused by a combination of bad luck, the environment and heredity-the model they developed may help quantify how much each factor, respectively, contributes to cancer development. 
2. No single factor causes cancer; cancer is caused by a combination of many factors.

3. Primary prevention-eliminating environmental factors and changing lifestyles-is the best way to prevent some types of cancer. One excellent example of primary prevention is quitting smoking.

4. Secondary prevention, that is, detecting and treating other types of cancer (while they are still curable), is the best way to prevent death from cancer.

5. Some cancers are best impacted by primary prevention vs. secondary prevention and vice-versa. ${ }^{9}$

If we are to enhance a patient's insight of his/her healthspan risks, surely the development of a therapeutic relationship that has at its heart a context of intellectual integrity must be used to frame advisory language, which better reflects the limitations that professionals understand and patients intuitively suspect. The necessity of balancing biological inevitability against personal and environmental risk while appreciating an individual's humanity, that is, his/her dynamic and fluid threshold of tolerance to personal risk, may lead to a more persuasive intellectual appeal. Treating people as an end point in a policy- and funding-driven algorithm of clinical "policybased" practice may not. People instinctively perceive from which end of the telescope their health information arises.

Until precision medicine becomes a part of routine medical practice and to some extent supplants the high level of reliance placed on an epidemiological projection of individual risk based on the statistical analysis of a cohort, an entirely natural threshold of individual risk tolerance appears potentially likely to persist as one of several ceilings that can inhibit patient participation both with an individual practitioner and with wider public health messages. Recognition of this limitation may also assist a practitioner toward considering engagement with a model of patient-centric care, which may have the added utility of reducing the burden on a single knowledge authority. Such an approach may help facilitate patient engagement by positioning the patient at the centre of a dialogue with a variety of medical, healthcare, and fitness providers.

Such positioning may be augmented and supported by technology, particularly around the recording, weighing, and encouragement of lifestyle choice and prevention to which this model may appear better suited than, for example, the management of a dreaded disease, which requires a patient-centred approach, where the practitioner occupies out of necessity, a patient-engaged central position at the centre of complex medical information. ${ }^{11}$

\section{REFERENCES}

1. Collins FS, Varmus H. A new initiative on precision medicine. N Engl J Med 2015;372:793-795.

2. How promising is precision medicine? [Internet]. 2016 Sep 29 [Cited 2016, Nov 11]. Available from: http://www.medscape.com/viewarticle/869483

3. The Precision Medicine Initiative, All of Us Research Program. US Department of Health and Human Services, National Institutes of Health, para 2. https://www.nih.gov/precision-medicine-initiativecohort-program

4. Stern V. 5 things you need to know about precision medicine. [Internet]. 2016 Sep 28 [Cited 2016, Nov 13]. Available from: http://www.medscape.com/viewarticle/869211

5. Saltelli A, Giampietro M. The fallacy of evidencebased policy. In Benessia A, Funtowicz S, Giampietro $\mathrm{M}$ et al. The Rightful Place of Science: Science on the verge. 2016, pp.57. Tempe, AZ. Consortium for Science, Policy and Outcomes.

6. Garcia-Valles R, Gomez-Cabrera MC, RodriguezMañas L et al. Life-long spontaneous exercise does not prolong lifespan but improves health span in mice. Longevity and Healthspan, 2013;2:14-28.

7. McGrath MC. Editorial - Can a cricket ball influence societal change? Exemplifying societal dichotomy in the tolerance of risk. Australasian Medical Journal, 2014;7(12):518-521. http://dx.doi.org/10.4066/AMJ.2014.2304

8. Tomasetti C, Vogelstein B. Variation in cancer risk among tissues can be explained by the number of stem cell divisions. Science 2015;347:78-81.

9. Tomasetti C, Vogelstein B. [PDF] Musings on the theory that variation in cancer risk among tissues can be explained by the numbers of divisions of normal stem cells. (address of statistical and technical issues) [Internet] 2015. [Cited 2016, Nov 13] Available from: https://arxiv.org/pdf/1501.05035

10. Tomasetti C, Vogelstein B. Bad luck of random mutations plays predominant role in cancer, study shows. (address of non-technical issues) [Internet 2015 Jan 1 \& Jan 7]. Cited 2016, Nov 13] Available from:

http://www.hopkinsmedicine.org/news/media/rele ases/bad_luck_of_random_mutations_plays_predo minant_role_in_cancer_study_shows

11. Patient Centric-Care Differs from Patient-Centred Care [Internet]. 2012 Mar 16 [Cited 2017, Jan 25] 
Available from:

https://davidleescher.com/2012/03/03/howpatient-centric-care-differs-from-patient-centeredcare-2/

\section{ACKNOWLEDGEMENTS}

None

\section{PEER REVIEW}

Not commissioned. Externally peer reviewed.

\section{CONFLICTS OF INTEREST}

The author declares that they have no competing interests.

\section{FUNDING}

None

ETHICS COMMITTEE APPROVAL

None 